\title{
THE CRITICAL SPACE INFRASTRUCTURE AND ITS IMPORTANCE TO MILITARY OPERATIONS
}

\author{
Marin-Marian COMAN, Dorel BADEA \\ "Nicolae Bălcescu" Land Forces Academy, Sibiu, Romania \\ coman.marian@gmail.com, dorel.badea@yahoo.com
}

\begin{abstract}
Actual scientific approaches related to critical infrastructure reveal its importance within many of the society's essential services that are necessary for day-to-day people's life. Besides other critical infrastructure systems, the emerging development of the space system results in the embedment of it within the critical space infrastructure concept that is based on its description related to the importance of the services provided to population, public or governing institutions, and industry. This paper intends to present the manner in which the space system services influence population's life and to emphasize the importance of the space infrastructure related to the process of planning and conducting military operations. The reliability and well functioning of the space system from the perspective as a critical infrastructure proves its paramount importance related to essential services provided to the population that results into social well-being. Nowadays, the majority of military operations depend on the development of space infrastructure and its reliability. Moreover, the military space operations are based on satellite control system architectures as well as the interconnected systems on surface and underground systems. From this side, the protection of critical space infrastructure and its resilience level should have a paramount value for all stakeholders that are using the space system services.
\end{abstract}

Keywords: critical space infrastructure, essential services, military operations, resilience

\section{Background information}

Today, when the word "smart" is present almost everywhere and is used in many process definitions or technical concepts, embedded in a proper manner into actual emerging technologies, gadgets or tools, our modern society is mainly based on providing and receiving reliable essential services that are indispensable for current life of the population. These essential services necessary for social well-being, industry and economy are provided by the critical infrastructure (CI) that is specific and identified by each country. In brief, from the perspective of the theory linked to a system of systems, a critical infrastructure could be defined as an interrelated body of systems, assets and networks that has as the main task its continued operations that are required for ensuring the essential services and security of a nation, its economy, and the public's health.

The United States Department of Homeland Security (DHS) provides a relevant definition of critical infrastructure: "critical infrastructure describes the physical and cyber systems and assets that are so vital to the United States that their incapacity or destruction would have a debilitating impact on our physical or economic security or public health or safety. The nation's critical infrastructure provides the essential services 
that underpin American society" [1]. DHS identifies the following 16 critical infrastructure sectors: Chemical; Commercial facilities; Communications; Critical manufacturing; Dams; Defence industrial base sector; Emergency services; Energy; Financial services; Food and agriculture; Government facilities; Healthcare and public health; Information technology; Nuclear reactors, materials, and waste sector; Transportation systems; Water and wastewater systems sector. The critical infrastructure sectors usually contain subsectors that are interdependent in providing essential services to population.

The 2008 Directive on European Critical Infrastructures (ECI), as a key pillar of the European Programme for Critical Infrastructure Protection (EPCIP), establishes the procedure for identification, designation, and a common approach for assessing the need to improve European Critical Infrastructures protection. The Directive provides the following definition of a critical infrastructure: "an asset, system or part thereof located in Member States which is essential for the maintenance of vital societal functions, health, safety, security, economic or social well-being of people, and the disruption or destruction of which would have a significant impact in a Member State as a result of the failure to maintain those functions" [2].

Generally, based on a nation's resources, needs, and economic development level, every country has its own procedure for deeming an infrastructure as being critical. This is the reason why the number of the identified critical infrastructures vary from one country to another.

The ECI Directive identifies 11 critical infrastructure sectors: Energy; Nuclear industry; Information, communication technologies ICT; Water; Food; Health; Financial; Transport; Chemical industry; Space; Research facilities.

The Annex 1 of the Government Emergency Ordinance 98/2010 of the Government of Romania [3] identifies 10 critical infrastructure sectors: Energy; Information technology and communications; Water supply; Food; Health; National security; Administration; Transport; Chemical and nuclear industry; Space and research.

The critical infrastructures have to be protected because they are vulnerable to many threatening internal or external factors. The quality of a critical infrastructure to reduce vulnerabilities, to minimize the threats' consequences, to adapt, to accelerate response to any threat or to have less time for recovering are part of a very fashionable concept named resilience.

The consequences that follow every destruction or disruption related to the functioning of critical infrastructure that could appear after each threat against it, have to be reduced quickly enough for reestablishing the proper operating conditions of that critical infrastructure.

As a research framework for this article, besides intuitive methods that were used for referring to the novelty elements and qualitative modifications, the exploratory methods that are based especially on contextual representations for knowing the useful landmarks in the purpose of objectivizing the investigated field related to critical space infrastructure were also applied.

\section{From space infrastructure to critical space infrastructure}

As it was previously presented in the introduction part of the article, there is not a steady total number of critical infrastructure sectors for each country and it depends on every country's policy and own procedure for identifying and designing a certain infrastructure as being critical, based on the essential services provided or on their implications into the well-being of the population. The Space system appears identified and defined as critical infrastructure sector by the European Critical Infrastructures Directive as "Space" or by the Government Emergency Ordinance 98/2010 of the Government of Romania as "Space and research". In addition, other countries identify the space system as a 
critical infrastructure sector.

Based on the essential services provided by the space system and its real influence on society's life, economic or defense sector, in this subchapter we will emphasize the importance of the space infrastructure and define it as being a critical sector similar to other critical infrastructure sectors that provide and interact with each other for the well-being of the population's day-to-day life.

Space systems have become key enablers of a wide variety of technologies and activities that are central to contemporary societies. They provide communications, remote sensing, positioning, navigation, synchronization, and other services, mainly based on information, which then become products like command-and-control capabilities, coordination of supply chains, as well as crisis and emergency situation management [4].

Nowadays the population is ever-more dependent on emergent technologies and the majority of the people are using the word "smart" when they have to discuss about a technological issue. World's population becomes more and more reliant on those smart technologies that are enabled by space systems. One of the great features of space infrastructure is represented by its potential to ensure the informational flux necessary for reliable communications or huge data traffic.

Space is congested, contested, and competitive, but space also touches most of the world's inhabitants. Directly or indirectly, everyone on Earth is affected and involved. Voluntarily or not, we are all now a part of the "space community". Space, along with its adjacency, cyberspace, has joined the domains of land, sea, and air as part of an interwoven, global, critical infrastructure providing essential information and connectivity [5].

A short history related to the space system evolution is necessary for understanding the reality that is in outer space, near the Earth, right "above our heads".

Between 1930s and 1940s, Nazi Germany studied a new weapon type - the longdistance missile. The 200-mile-range V-2 rockets were employed during World War II for attacking some cities such as London. The V-2 rockets flew with roughly 3500 miles per hour and had an arch over the English Channel of 60 miles high. Besides the real terror of using V-2 missiles during attacks, the German rockets proved a new successful technological advance at that time and an important step for conquering the outer space was done.

The discoveries related to rockets' building and launching done by Germany during World War II were prerequisites for the Soviet Union and the United States to create their own space programs. The first satellite in the world named Sputnik 1 was launched by Soviets on October $4^{\text {th }}, 1957$. Then, the Russian space program evolved and Yuri Gagarin became the first man who flew in the space on April 12 $2^{\text {th }}, 1961$. The flight around the Earth with Vostok 1 was accomplished in 108 minutes and Gagarin's spacecraft reached a maximum height of 203 miles (327 kilometers).

After the first artificial satellite successfully launched in the space, a new face of Cold War named Space Race began and it was the turn for the United States to prove its superiority and supremacy in conquering the space. Explorer 1 was the first satellite launched on January $31^{\text {st }}, 1958$. It orbited the Earth from as far as 1,594 miles $(2,565 \mathrm{~km})$ above and made the first scientific discovery in space - the Van Allen radiation belt that refers specifically to the radiation belts surrounding the Earth. Then the first landing on the moon with human crew was successfully conducted by Apollo 11 spaceflight on July $20^{\text {th }}, 1969$.

The launches in the outer space of the two first satellites in the world were done with the occasion of an international scientific project - the International Geophysical Year (IGY) - that lasted from July $1^{\text {st }}, 1957$, to December $31^{\text {st }}, 1958$ and replaced the International Polar Year event.

IGY encompassed researches pertaining to 11 fields of geophysics: aurora and airglow, 
cosmic rays, geomagnetism, glaciology, gravity, ionospheric physics, longitude and latitude determinations, meteorology, oceanography, seismology, and solar activity [6].

After those paramount international events on 1957 and 1958 related to the launch in the space of the first artificial satellites, a new Era of Space Exploration began. Scientific researches on space were possible due to many satellite launches over time. The rocket field and launching methods of artificial satellites have been evolving in the last decade. The space industry has been making lots of researches and discoveries that have influenced our daily life.

Starting from 1957 until 2019, an impressive number of artificial objects comprising satellites and probes that are orbiting around Earth were launched. (Figure 1) Some of the launched probes have the mission to study the Sun and other planets from our solar system.

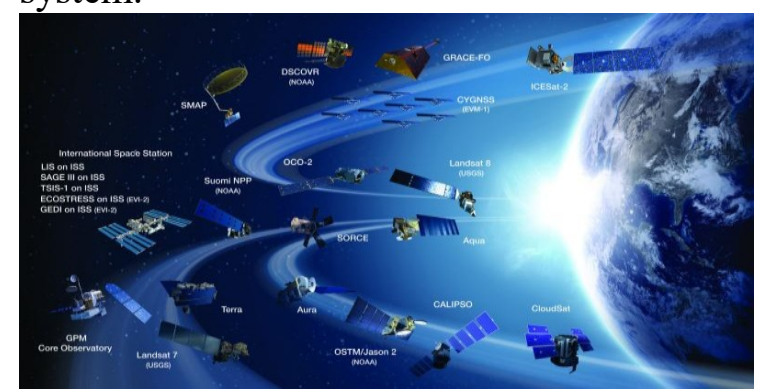

Figure 1: Picture of satellites orbiting the Earth - NASA's Earth Observing System Project Science Office [7]

The United Nations Office for Outer Space Affairs (UNOOSA) states in the Index of Objects Launched into Outer Space "there were 4,987 satellites orbiting the planet at the start of the year, an increase of $2.68 \%$ compared to 2018. However, of this number only 1,957 are currently active indicating that there is a lot of flying metal out there in space. In addition to all of these satellites, there are thousands of uncontrolled rocket bodies orbiting earth, along with more than 20,000 artificial objects floating around" [8]. Among artificial satellites that have been orbiting the Earth, a special space object can be seen with naked eye in some days with clear sky - the International Space Station
(ISS). ISS is a habitable artificial satellite in the low Earth orbit, which consists of pressurized habitation modules, structural trusses, solar arrays, radiators, docking ports, experiment bays and robotic arms. It flies $400 \mathrm{~km}$ high at a roughly speed of 28800 $\mathrm{km} / \mathrm{h}$ taking only 90 minutes to make a complete circuit of the Earth and serves as a microgravity and space environment research laboratory in which crewmembers conduct experiments in biology, human biology, physics, astronomy, meteorology, and other fields. The ISS programme is a joint project between five participating space agencies: NASA (National Aeronautics and Space Administration - US), ROSCOSMOS (Russia), JAXA (Japan Aerospace Exploration Agency - Japan), ESA (European Space Agency - Europe), and CSA (Canadian Space Agency - Canada).

The advance of space technology has as a result the emerging space industry that was released more and more in the last decade and has been growing today. New space based businesses are developing in an accelerated trend of economic growth.

During a panel session of New Space conference 2018 held by Space Frontier Foundation it was announced that "several reports in the last year by investment banks predicted that the global space economy, currently valued at about $\$ 350$ billion, could grow to $\$ 1$ trillion or more in the 2040s"[9]. As an example, SpaceX is one of the top and the most innovative companies in 2018, founded in 2002 by Elon Musk, which has been using the space systems for developing its business. "In 2017, the company boldly went where no aerospace start-up has gone before, posting 18 successful launches twice as many as in the previous year - on behalf of companies in five countries, as well as the Air Force, NASA, and the topsecret U.S. National Reconnaissance Office. SpaceX delivered 48 satellites into orbit and 22,700 pounds of supplies to the International Space Station, and now holds more than $60 \%$ of the global share of commercial launch contracts" [10].

The services provided by the space system to 
population, government institutions, industry and military field, and the interdependencies between those services with other kind of critical infrastructure services prove the real importance and the critical side of the space infrastructure as an essential services provider.

\section{The space system as part of military operations}

Nowadays, the services such as Earth observation and remote sensing, internet and all communications' types, navigation, positioning and timing are provided all over the world by the satellites or satellite constellations that are part of the space infrastructure. "These capabilities supplement or complement those of critical terrestrial infrastructure systems, enhancing them. For example, global transport systems today are increasingly dependent on Global Navigation Satellite Systems (GNSS)" [11].

The employment of space system and the services provided by it for military purposes have proved a new perspective of actual military operations conduct. The operational environment of future conflicts will require a deeper consideration of the space infrastructure that has to be taken into consideration for operational planning and claims the development of strategic space capabilities. Moreover, the monitoring process of smart weapons, guided ammunition and the tracking possibilities of military forces in the battlefield during military actions are prerequisites for any military operations' success.

According to the website worldatlas.com, the United States has 123 military satellites, Russia owns 74 military satellites, and China has 68 satellites set for military use.

After the first launch of the US Discoverer-1 satellite in 1959, there have been several projects including Corona, Canyon, Aquacade, Orion, Magnum, and Trumpet. The latest satellite to be launched was a Wideband Global SATCOM (WGS-9). The satellite was built by Boeing and was the ninth to be launched as part of a ten-member satellite project by the US Air Force. The satellites are to be used for communication. Intelsat is a commercial satellite operator, and it is managed by the US military space units. The Chinese space program dates back to the 1950s. The military operated satellites are named Yaogan. Yaogan 30D, 30E, and 30F were launched on November 24, 2017. The three are said to be experimental and are to be used for intelligence gathering [12].

According to www.n2yo.com "on December $2^{\text {nd }}, 2017$, Russia launched COSMOS 2524, a military surveillance satellite designed to monitor adversaries' radio signals, detecting, tracking, and destroying of any missiles. Analysts believe the satellite is the third in the Russian military's series of Lotos electronic intelligence-gathering missions, following the launch of a Lotos test satellite in November 2009 and a follow-up launch of the first Lotos-S1 payload in December 2014" [13].

Another important service provided by the space infrastructure is linked to the use of military drones or UAVs (unmanned aerial vehicles). The positioning, real control and piloting of the military drones are conducted with the help of satellite constellations. (Figure 2)

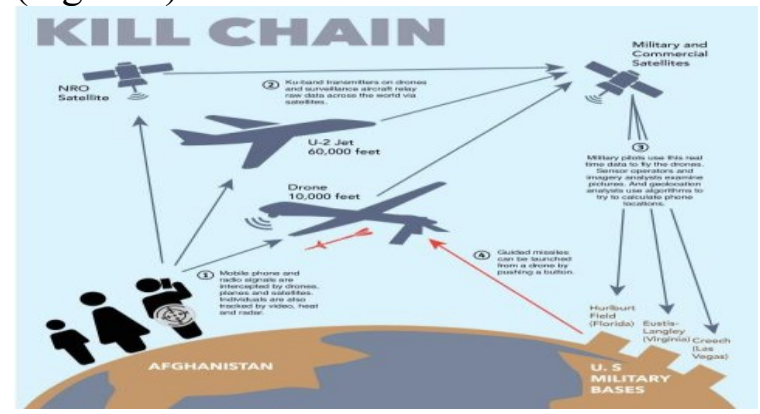

Figure 2: A way of using the military drone during military operations [14]

Nowadays, these robotic enablers are present in the battlefield and their employment result in a great advantage for the armed forces that use drones during military operations conduct.

The 2018 Joint Publication 3-14 states that "Space assets provide commanders with near-worldwide coverage and access to otherwise denied areas. Commanders should account for specific space characteristics to plan and operate effectively" [15]. 


\section{Conclusions}

The space infrastructure has become a critical component of the wider infrastructure system that provides great capabilities and essential services to industry, government institutions, and population. Space systems are critical enablers for the majority of the services starting from communications, internet network, television broadcasting, geopositioning and navigation, to Earth observation and remote sensing.

Based on the continuous and increasing dependence of essential services provided by space systems, which play a key role for the well-being of the entire society, the space infrastructure could be easily embedded into the concept of critical space infrastructure.

The employment of space systems and satellites within the military domain has a great importance for military operations' success and result in space situational awareness, space control, missile warning, nuclear detonation detection, satellite communications, space lift, environmental monitoring, positioning, navigation, and timing, and surveillance, intelligence and reconnaissance.

\section{References}

[1] https://www.dhs.gov/cisa/infrastructure-security

[2] Council Directive 2008/114/EC, published in the Official Journal of the European Union at 23.12.2008, available at https://eurlex.europa.eu/LexUriServ/LexUriServ.do?uri=OJ:L:2008:345:0075:0082:EN:PDF

[3] Government Emergency Ordinance 98/2010, Annex no. 1, available at https://lege5.ro/Gratuit/geztqmzxhe/ordonanta-de-urgenta-nr-98-2010-privindidentificarea-desemnarea-si-protectia-infrastructurilor-critice

[4] Liviu Mureșan, Alexandru Georgescu, The Road to Resilience in 2050 - Critical Space Infrastructure and Space Security, The RUSI Journal, Vol. 160, Issue 6, pp. 59, 2015

[5] National Academies of Sciences, Engineering, and Medicine, National Security Space Defense and Protection: Public Report, Washington, DC: The National Academies Press, pp. 7, 2016, available at https://www.nap.edu/read/23594/chapter/2\#7

[6] https://www.britannica.com/event/International-Geophysical-Year

[7] https://eospso.nasa.gov/

[8] https://www.euspaceimaging.com/the-lifespan-of-orbiting-satellites/

[9] https://spacenews.com/a-trillion-dollar-space-industry-will-require-new-markets/

[10] https://www.fastcompany.com/company/spacex

[11] Liviu Mureșan, Alexandru Georgescu, The Road to Resilience in 2050 - Critical Space Infrastructure and Space Security, The RUSI Journal, Vol. 160, Issue 6, pp. 60, 2015

[12] https://www.worldatlas.com/articles/countries-by-number-of-military-satellites.html

[13] https://www.n2yo.com/satellite/?s=43032

[14] https://corpwatch.org/article/drone-inc-k-embedded-kill-chain

[15] Joint Publication 3-14, Space Operations, 10 April 2018, pp. I-4 